\title{
IN VITRO STUDY TO EVALUATE THE EFFECT OF 45S5 BIOGLASS PASTE AND Er,Cr:YSGG 2780 nm LASER ON RE-MINERALIZATION OF ENAMEL WHITE SPOT LESIONS (ENERGY DISPERSIVE X-RAY ANALYSIS AND STEREOMICROSCOPIC ASSESSMENTS)
}

\author{
Eman Atef Kamel *, Mostafa E. Geith ${ }^{* *}$ and Dina M.M.El-Said M. Hassouna***
}

\begin{abstract}
BACKGROUND: White spot lesions (WSLs) are one of the common problems which occur on enamel surface around bonded brackets following orthodontic treatment.

AIM: Evaluate the effect of Er,Cr:YSGG $(\lambda=2780 \mathrm{~nm})$ laser and $45 \mathrm{~S} 5$ bioactive glass (BAG) paste either alone or in combination on re-mineralization of enamel white spot lesions.

MATERIAL AND METHODS: 50 enamel samples with induced WSLs. There are 5 groups $(\mathrm{n}=10)$. Group 1, control; Group 2, 45S5 BAG paste treatment only; Group 3, Er,Cr:YSGG laser irradiated $(0.5 \mathrm{~W}, 20 \mathrm{~Hz}, 10 \mathrm{~s})$ alone, Group 4, 45S5 BAG paste treatment applied before irradiation with same laser parameters in group 3 and Group 5, 45S5 BAG paste treatment applied after laser irradiation. Enamel surface was assessed morphologically by stereomicroscope and Mineral content analysis by Energy Dispersive X-ray Analysis (EDXA). The results were statistically analyzed.
\end{abstract}

RESULTS: EDXA revealed the highest $\mathrm{Ca}, \mathrm{Ca} / \mathrm{P}$ ratio and least $\mathrm{C}$ mass $\%$ in group 4 . The highest $\mathrm{P}$ mass\% in group 5. Stereomicroscopic results of outer enamel surface revealed that WSLs were reduced in group 2 while disappeared in group 3, 4 \& 5. Group 4 showed more translucent enamel surfaces, whereas group 5 showed homogenous radio-opaque enamel surface. Stereomicroscopic results of enamel subsurface revealed the least M.B dye penetration depth in group 3 followed by 5, 4, 3, 2 and 1 respectively.

CONCLUSIONS: 45S5 BAG paste treatment before Er,Cr:YSGG laser showed the best remineralized enamel surface with complete absence of WSLs.

KEYWORDS: WSLs, Enamel re-mineralization, Er,Cr:YSGG laser, 45S5 BAG paste, EDXA.

\footnotetext{
* Post Graduate Student For Master Degree in Laser Applications in Dental Surgeries National Institute of Laser Enhanced Sciences, Cairo University

** Professor of Laser Applications in Dental Surgeries National Institute of Laser Enhanced Sciences, Cairo University. *** Lecturer in Oral Biology Department, Faculty of Dentistry, Fayoum University.
} 


\section{INTRODUCTION}

WSLs are one of the most common problems which occur on tooth enamel surface around bonded brackets after prolonged orthodontic treatment. WSLs occur due to demineralization of enamel. Enamel demineralization develops as a result of long term bacterial plaque accumulation on enamel surface. Moreover, enamel demineralization leads to loss of enamel translucency and formation of initial non cavitated carious lesion. Thus, WSLs have a chalky white appearance which presents a major esthetic and clinical problem in dental clinics (Gillgrass et al., 2001; Sudjalim et al., 2006; Taha et al., 2017; Ciftci et al., 2018 and Yagci et al., 2019).

WSLs may be re-mineralized either physiologically through minerals found naturally in saliva (Belikov et al., 2008) or externally by topical application of re-mineralizing agents (Taha et al., 2017; Bakry et al., 2018). Among the topical re-mineralizing agents used are; fluoride, casein phosphopeptide-amorphous calcium phosphate, low viscosity resin "infiltrate" and BAG paste. These agents are supplied in the form of varnishes, pastes, mouth rinses, solutions, gels or chewing gums (Bakry et al., 2014; Oliveira et al., 2014; Milly et al., 2015; Sugiura et al., 2016; Ebrahimi et al., 2017; Borges et al, 2017; Bakry et al., 2018; Çiftçi et al., 2018; Giray et al., 2018; Prasada et al., 2018).

45S5 BAG (BAG) has been developed for dental use and applied in plethora of studies to re-mineralize enamel WSLs (Bakry et al., 2014; Bakry et al., 2014; Milly et al., 2014; Narayana et al., 2014; Milly et al., 2015; Taha et al, 2018; Abbassy et al., 2019). 45S5 BAG has shown promising results in inducing hydroxyapatite formation when brought in contact with saliva by forming a calcium phosphaterich layer which can bond chemically to enamel surface ( Hench, 2006; Bakry et al., 2011; Sfalcin et al., 2019).

Laser is among the new techniques used in treatment of WSLs. Whereas, laser interacts photothermally and photo-mechanically with enamel. Laser/Enamel interaction results in recrystallization of enamel crystallites, reduction in enamel permeability, thus increases acids resistance and enhances enamel melting which seal enamel surface (Kawasaki et al., 2000; Hossain et al., 2001; Tsai et al., 2002; Fried, 2005; Maung et al., 2007; Allam et al., 2018).

Among the lasers which were used in enamel remineralization either alone or in combination with other topical agents were carbon dioxide, Nd:YAG, Er:YAG and Er,Cr:YSGG laser (Poosti et al., 2014; Ceballos-Jimenez et al., 2018; Abufarwa et al., 2019; El Mansy et al., 2019; Serdar-Eymirli et al., 2019).

Little literature had been reported regarding the effect of Er,Cr:YSGG laser on enamel remineralization either alone or in combination with other topical agents (Allam et al., 2018, Elwardani et al., 2019; Serdar-Eymirli et al., 2019). However, the effect of Er,Cr:YSGG laser in combination with 45S5 BAG is still not obvious which led to the aim of this study. The aim of this study is to evaluate the effect of Er,Cr:YSGG $2780 \mathrm{~nm}$ laser and 45S5 BAG paste either alone or in combination with each other in re-mineralization of enamel WSLs.

\section{MATERIAL AND METHODS:}

Twenty-five non-carious human premolars, extracted for orthodontic reasons were collected from the out-patient clinics of Faculty of Oral and Dental Medicine, Alexandria University after obtaining patient consent and acceptance from Research Ethics Committee of Laser Applications 
in Dental Surgeries National Institute of Laser Enhanced Sciences - Cairo University. The teeth were cleaned and kept hydrated in saline solution. Teeth were sectioned mesio-distaly in a vertical direction into buccal and lingual halves using very thin diamond disc with low speed micro motor under water spray to avoid heat generation, so that each half has one sound enamel surface. Finally, fifty halves of sound enamel surface were obtained.

In order to acquire a WSL on sound enamel surface, area of application was created by using a dark nail polish to cover the whole enamel surface of each sample except a rectangular window of size $3 \mathrm{~mm} \times 4 \mathrm{~mm}$ at the middle. Then all samples were immersed in the demineralizing solution at room temperature and after four days, samples were washed with distilled water and dried with air. Finally, WSLs were observed upon changing the enamel color into white chalky.

Samples then divided randomly into 5 groups $(\mathrm{n}=10)$. The experimental groups were: Group 1, untreated (control); Group 2, 45S5 BAG paste treated; Group 3, Er,Cr:YSGG laser irradiated; Group 4, 45S5 BAG paste treated then Er,Cr:YSGG laser irradiated and Group 5, Er,Cr:YSGG laser irradiated then 45S5 BAG paste treated.

45S5 BAG paste treatment was done by applying a mix of one tenth of a gram of 45S5 BAG powder and $0.2 \mathrm{ml}$ of $50 \mathrm{wt} \%$ phosphoric acid, to the area of application using a micro brush and adapted using celluloid strip. Then, a thin layer of light cure bonding agent is used to cover the paste and light cured for 20 seconds. Paste removed after 5 minutes using excavator and samples rinsed with water spray.

Er,Cr:YSGG $2780 \mathrm{~nm}$ laser irradiation was applied to the area of application using gold hand piece and MZ5 zirconia tip (diameter $0.5 \mathrm{~mm}$, spot size $1 \mathrm{~mm}$ ) in scanning motion (back and forth) covering the surface area of application completely. Laser irradiation parameters were $0.5 \mathrm{~W}$ with frequency $20 \mathrm{~Hz}$ for 10 seconds in non-contact mode and continuous wave beam with $20 \%$ Air and $10 \%$ water. All samples of all groups were then immersed in artificial saliva solution for 10 days at room temperature before assessment. Elemental analysis for Calcium (Ca), Phosphorus (P), Carbon (C), in terms of mass \%, of enamel surface in all groups was performed by EDXA.

Morphological assessment was done by examination of all samples by Stereo microscope from the outer surface of enamel at original magnification $\mathrm{X}$ 25 and from enamel subsurface at original magnification X 80. The penetration depth of M.B dye in terms of length $(\mathrm{mm})$ and area $\left(\mathrm{mm}^{2}\right)$ for all samples were measured.

Statistical analysis was done using F-test (ANOVA) for normally distributed quantitative variables, to compare between more than two groups, and Post Hoc test (Tukey) for pairwise comparisons. Data carried out for statistical analysis were $\mathrm{Ca}, \mathrm{P}$, $\mathrm{C}$ mass $\%$ and $\mathrm{Ca} / \mathrm{P} \%$ as well as penetration depth of M.B dye in terms of length (mm) and area $\left(\mathrm{mm}^{2}\right)$. 
TABLE (1): Showing composition of chemicals and reagents used in this study.

\begin{tabular}{|c|c|c|c|}
\hline $\begin{array}{c}\text { Chemicals \& Reagents } \\
\text { Artificial saliva }\end{array}$ & $\begin{array}{l}\quad \text { Composition } \\
\mathrm{NaCl} 0.4 \mathrm{gm} \\
\mathrm{KCl} 0.4 \mathrm{gm} \\
\mathrm{CaCl}_{2} 0.795 \mathrm{gm} \\
\mathrm{NaH}_{2} \mathrm{PO} \text { (Mono basic) } 0.78 \mathrm{gm} \\
\mathrm{Urea}_{1} \mathrm{gm} \\
\text { Aqua to } 1000 \mathrm{ml}\end{array}$ & $\begin{array}{l}\text { References } \\
\text { (Pytko- } \\
\text { polonczyk et } \\
\text { al., 2017) }\end{array}$ & $\begin{array}{l}\qquad \text { Purchased and prepared from } \\
\text { Khalil Pharmacy, Raml station, Alexandria - } \\
\text { Egypt. }\end{array}$ \\
\hline $\begin{array}{l}\text { Demineralizing } \\
\text { solution }\end{array}$ & $\begin{array}{l}2.2 \mathrm{mM} \mathrm{CaCl}_{2} \\
10 \mathrm{mM} \mathrm{NaH}_{2} \mathrm{PO}_{4} \\
50 \mathrm{mM}_{\text {acetic acid }} \\
100 \mathrm{mM} \mathrm{NaCl} \\
1 \mathrm{ppm} \mathrm{NaF} \\
0.02 \% \mathrm{NaN}_{3} \\
\mathrm{pH} 4.5\end{array}$ & $\begin{array}{l}\text { (Bakry et al., } \\
\text { 2014) }\end{array}$ & $\begin{array}{l}\text { Applied Medical Chemicals Department, } \\
\text { Medical Research Institute - Alexandria } \\
\text { University, Egypt. }\end{array}$ \\
\hline 45S5 BAG powder & $\begin{array}{l}24.5 \mathrm{wt} \% \mathrm{Na}_{2} \mathrm{O} \\
24.4 \mathrm{wt} \% \mathrm{CaO} \\
6 \mathrm{wt} \% \mathrm{P}_{2} \mathrm{O}_{5} \\
45 \mathrm{wt} \% \mathrm{SiO}_{2}\end{array}$ & $\begin{array}{l}\text { (Bakhsh et al., } \\
\text { 2017) }\end{array}$ & $\begin{array}{l}\text { Ready made from XL Sci-Tech, Inc. Company, } \\
\text { Richland, Washington - USA. }\end{array}$ \\
\hline $\begin{array}{c}\text { Phosphoric acid } 50 \\
\text { wt. \% }\end{array}$ & $\begin{array}{l}\text { prepared by dilution of } 85 \mathrm{wt} \% \\
\text { phosphoric acid with distilled } \\
\text { water }\end{array}$ & $\begin{array}{l}\text { (Bakry et al., } \\
\text { 2011) }\end{array}$ & $\begin{array}{l}\text { Supplied by SDFCL company, Mumbai and } \\
\text { purchased readymade from El-Goumhouria } \\
\text { CO. for trading medicines, Cairo - Egypt. }\end{array}$ \\
\hline Saline & Sodium chloride $0.9 \% \mathrm{~W} / \mathrm{V}$ & $\begin{array}{l}\text { (Bakhsh et al., } \\
\text { 2017) }\end{array}$ & $\begin{array}{l}\text { Produced by El Nasr Pharmaceutical } \\
\text { chemicals company purchased ready } \\
\text { made from El-goumhouria CO. for trading } \\
\text { medicines, Cairo - Egypt. }\end{array}$ \\
\hline
\end{tabular}

TABLE (2): Showing grouping of prepared samples.

\begin{tabular}{|c|l|}
\hline Group 1 & 10 samples received no treatment \\
\hline Group 2 & $\begin{array}{l}10 \text { samples treated with45S5 BAG paste } \\
\text { only }\end{array}$ \\
\hline Group 3 & $\begin{array}{l}10 \text { samples irradiated with Er,Cr:YSGG } \\
2780 \mathrm{~nm} \text { laser only }\end{array}$ \\
\hline Group 4 & $\begin{array}{l}10 \text { samples treated with 45S5 BAG paste } \\
\text { then irradiated with Er,Cr:YSGG 2780 nm } \\
\text { laser }\end{array}$ \\
\hline Group 5 & $\begin{array}{l}10 \text { samples irradiated with Er,Cr:YSGG } \\
2780 \mathrm{~nm} \text { laser then treated with 45S5 BAG } \\
\text { paste }\end{array}$ \\
\hline
\end{tabular}

\section{RESULTS}

\section{Stereomicroscope}

The outer surface of enamel stereomicroscopic assessment revealed; obvious WSLs in control group 1, reduction of WSLs appeared upon receiving 45S5 BAG paste only (group 2), cracks and melting for enamel surface appeared after being irradiated by Er,Cr:YSGG laser only (group 3) and absence of WSLs upon applying 45S5 BAG paste either before or after Er,Cr:YSGG laser irradiation (group 4 and 5 respectively). Whereas, transluscent enamel surface was obtained in group 4 when $45 \mathrm{~S} 5 \mathrm{BAG}$ paste applied before Er,Cr:YSGG laser irradiation. Moreover, more homogenous radio-opaque enamel 
surface was apparent when 45S5 BAG paste was applied after enamel surface has been irradiated by Er,Cr:YSGG laser (group 5) as shown in fig (1).

Enamel subsurface structure was also assessed by stereomicroscope to understand the extent of re-mineralization in various groups. Whereas, obliterated re-mineralized areas didn't allow M.B. dye to penetrate enamel subsurface and appeared white. Moreover, demineralized areas allowed M.B. dye to penetrate enamel subsurface and appeared blue. Stereomicroscopic enamel subsurface results revealed the least M.B dye penetration depth in group 3 followed by 5, 4, 3, 2 and 1 respectively with statistical significance $(\mathrm{P}<0.05)$ in terms of length $(\mathrm{mm})$ and area $(\mathrm{mm} 2)$ as shown in fig. (3\&4) and table (3\&4).

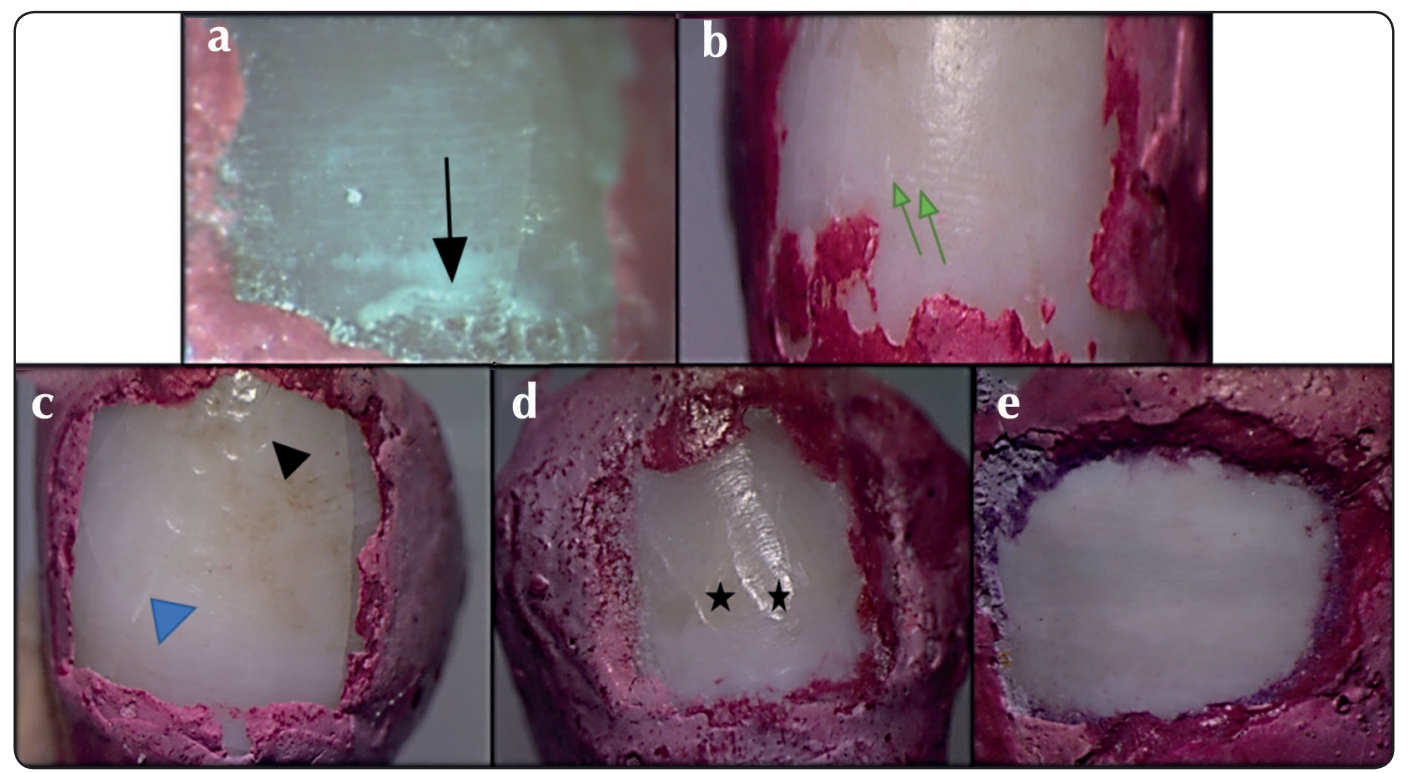

Fig. (1): Stereo micrograph plate of all studied groups showing the surface structure of enamel. (a) Group 1; showing induced WSL (black arrow), (b) Group 2; showing decreased amount of WSL (green arrow) (c) Group 3; showing enamel melting (black arrow head) and cracks (blue arrow head), (d) Group 4; areas of enamel translucencies (black stars) and (e) showing homogenous radio-opaque enamel surface. (Original magnification X 25)

TABLE (3): Showing comparison between the different studied groups according to penetration depth mm in terms of length.

\begin{tabular}{|c|c|c|c|c|c|c|c|c|c|}
\hline \multicolumn{2}{|c|}{ Group 1 } & \multicolumn{2}{c|}{ Group 2 } & \multicolumn{2}{c|}{ Group 3 } & \multicolumn{2}{c|}{ Group 4 } & \multicolumn{2}{c|}{ Group 5 } \\
\hline Mean & SD. & Mean & SD. & Mean & SD. & Mean & SD. & Mean & SD. \\
\hline 0.13680 & 0.00699 & 0.02641 & 0.00272 & 0.00001 & 0.000004 & 0.04490 & 0.00992 & 0.0001 & 0.00009 \\
\hline
\end{tabular}

TABLE (4): showing Comparison between the different studied groups according to penetration depth in terms of area $\mathrm{mm}^{2}$.

\begin{tabular}{|c|c|c|c|c|c|c|c|c|c|}
\hline \multicolumn{2}{|c|}{ Group 1 } & \multicolumn{2}{c|}{ Group 2 } & \multicolumn{2}{c|}{ Group 3 } & \multicolumn{2}{c|}{ Group 4 } & \multicolumn{2}{c|}{ Group 5 } \\
\hline Mean & SD. & Mean & SD. & Mean & SD. & Mean & SD. & Mean & SD. \\
\hline 0.08640 & 0.04578 & 0.0064 & 0.00357 & 0.00001 & 0.00001 & 0.00340 & 0.00143 & 0.00007 & 0.00003 \\
\hline
\end{tabular}




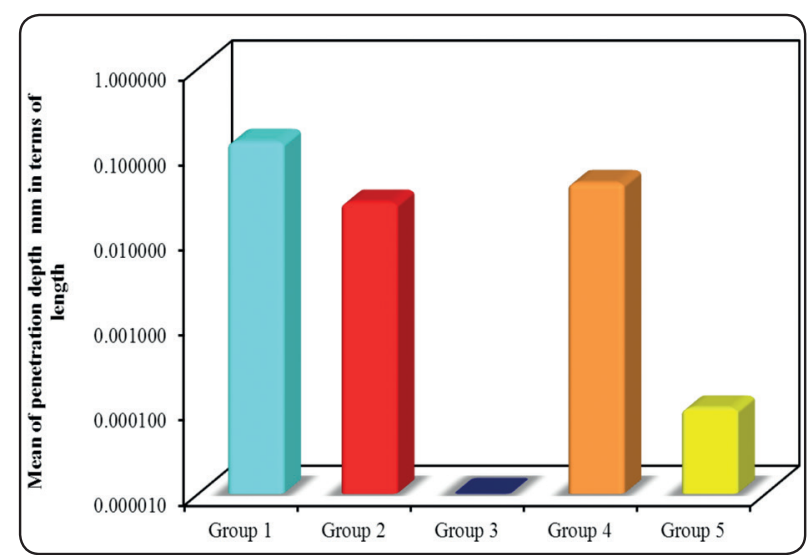

Fig. (2): Showing comparison between the different studied groups according to penetration depth in terms of length $(\mathrm{mm})$.

\section{Energy Dispersive X-ray Analysis (EDXA);}

EDXA statistical results revealed the highest $\mathrm{Ca}, \mathrm{Ca} / \mathrm{P}$ ratio mass $\%$ in group 4 and highest $\mathrm{P}$ and least $\mathrm{C}$ mass\% in group 5. The highest $\mathrm{Ca}$ mass \% was apparent in group 4 , where group 4 was non-statistically significant higher than group 5. Both groups were statistically significant higher $(\mathrm{P}<0.001)$ than group 3, 2 and 1 respectively in descending order as shown in table (5) and fig. (4). However, there was non-significant difference statistically between group 4 and group $5(\mathrm{p}>0.05))$.

The highest $\mathrm{P}$ mass $\%$ appeared in group 5 which was non-statistically significant higher than group

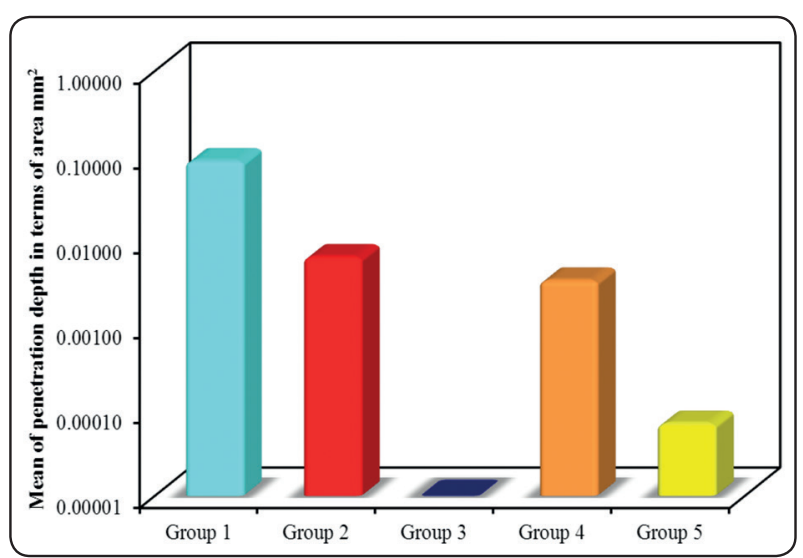

Fig. (3): showing comparison between the different studied groups according to penetration depth in terms of area $\mathrm{mm}^{2}$.

$4(\mathrm{p}>0.05)$. Both group $4 \& 5$ were statistically significant higher $\mathrm{P}<0.001$ than groups 3,2 and group 1 respectively in descending order as shown in table (6) and fig. (5). The highest $\mathrm{Ca} / \mathrm{P}$ ratio \% appeared in group 4 then decreased in descending order in groups 3, 5, 1 and 2 with no statistical significance ( $\mathrm{p}>0.05)$ as shown in table (7) and fig. (6). The highest mean value of $\mathrm{C}$ mass $\%$ appeared in group 1 than groups 3, 2, 4 and 5 with statistical significance $(\mathrm{P}<0.001)$ in descending order as shown in table (8) and fig. (7). Whereas, in treatment groups, group 3 showed the highest value and group 5 showed the least value. There was no statistical significance between group $4 \& 5(p>0.05)$.

Table (5): Showing comparison between the different studied groups according to Ca mass $\%$.

\begin{tabular}{|c|c|c|c|c|c|c|c|c|c|}
\hline \multicolumn{2}{|c|}{ Group 1 } & \multicolumn{2}{c|}{ Group 2 } & \multicolumn{2}{c|}{ Group 3 } & \multicolumn{2}{c|}{ Group 4 } & \multicolumn{2}{c|}{ Group 5 } \\
\hline Mean & SD. & Mean & SD. & Mean & SD. & Mean & SD. & Mean & SD. \\
\hline 10.26 & 5.0 & 18.56 & 3.98 & 23.40 & 1.32 & 28.73 & 1.21 & 27.64 & 3.37 \\
\hline
\end{tabular}

TABLE (6): Showing Comparison between the different studied groups according to P mass $\%$.

\begin{tabular}{|c|c|c|c|c|c|c|c|c|c|}
\hline \multicolumn{2}{|c|}{ Group 1 } & \multicolumn{2}{c|}{ Group 2 } & \multicolumn{2}{c|}{ Group 3 } & \multicolumn{2}{c|}{ Group 4 } & \multicolumn{2}{c|}{ Group 5 } \\
\hline Mean & SD. & Mean & SD. & Mean & SD. & Mean & SD. & Mean & SD. \\
\hline 6.71 & 2.51 & 10.95 & 0.70 & 12.48 & 0.41 & 14.40 & 0.81 & 14.82 & 0.91 \\
\hline
\end{tabular}


TABLE (7): Showing comparison between the different studied groups according to $\mathrm{Ca} / \mathrm{P} \%$.

\begin{tabular}{|c|c|c|c|c|c|c|c|c|c|}
\hline \multicolumn{2}{|c|}{ Group 1 } & \multicolumn{2}{c|}{ Group 2 } & \multicolumn{2}{c|}{ Group 3 } & \multicolumn{2}{c|}{ Group 4 } & \multicolumn{2}{c|}{ Group 5 } \\
\hline Mean & SD. & Mean & SD. & Mean & SD. & Mean & SD. & Mean & SD. \\
\hline 1.85 & 1.85 & 1.69 & 0.30 & 1.87 & 0.09 & 2.0 & 0.11 & 1.86 & 0.12 \\
\hline
\end{tabular}

TABLE (8): Showing comparison between the different studied groups according to $\mathrm{C}$ mass $\%$.

\begin{tabular}{|c|c|c|c|c|c|c|c|c|c|}
\hline \multicolumn{2}{|c|}{ Group 1 } & \multicolumn{2}{c|}{ Group 2 } & \multicolumn{2}{c|}{ Group 3 } & \multicolumn{2}{c|}{ Group 4 } & \multicolumn{2}{c|}{ Group 5 } \\
\hline Mean & SD. & Mean & SD. & Mean & SD. & Mean & SD. & Mean & SD. \\
\hline 37.24 & 1.98 & 22.23 & 5.50 & 25.96 & 2.31 & 15.92 & 1.48 & 13.14 & 2.70 \\
\hline
\end{tabular}

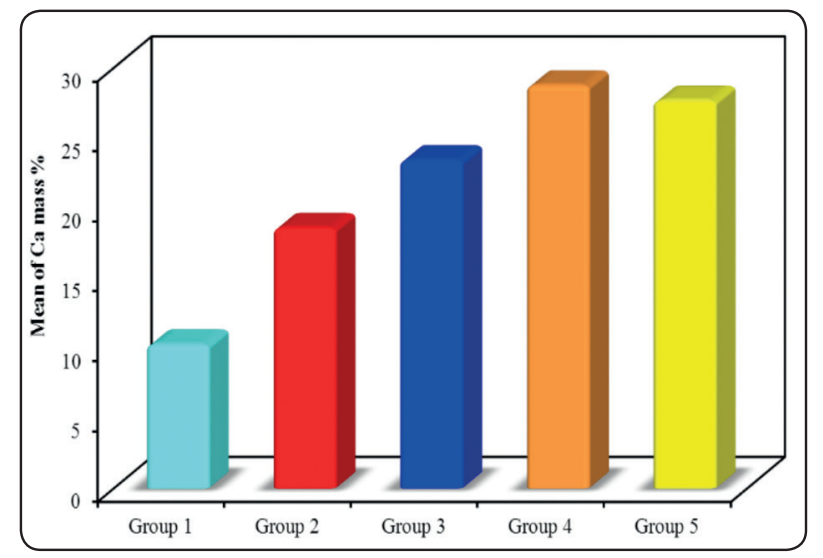

Fig. (4): Showing comparison between the different studied groups according to $\mathrm{Ca}$ mass $\%$.

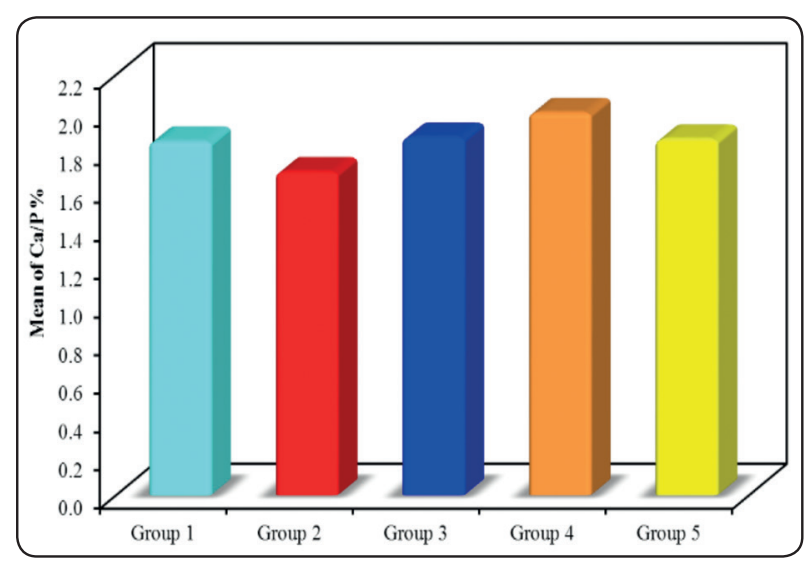

Fig. (6): Showing comparison between the different studied groups according to $\mathrm{Ca} / \mathrm{P} \%$.

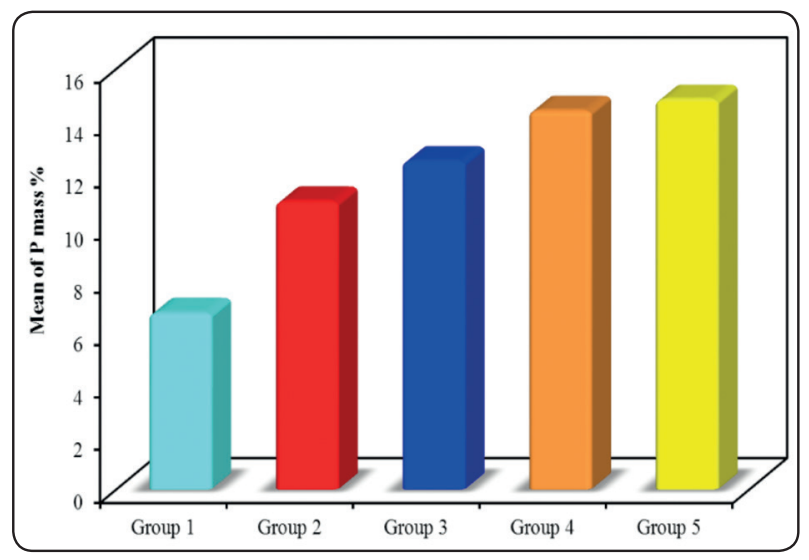

Fig. (5): Showing Comparison between the different studied groups according to $\mathrm{P}$ mass $\%$.

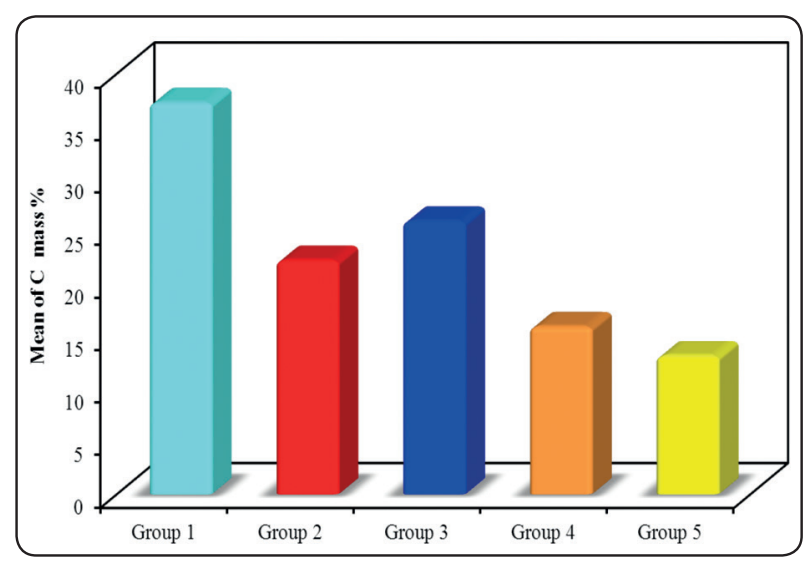

Fig. (7): Showing comparison between the different studied groups according to $\mathrm{C}$ mass $\%$. 


\section{DISCUSSION}

WSLs represents a major esthetical problem after orthodontic treatment. Managing early detected WSLs starts with re-mineralization therapies to arrest disease and to restore enamel strength and function with a variety of re-mineralizing agents (Cochrane et al., 2010; Borges et al., 2017; Abufarwa et al., 2018; Sindhu, 2019). 4S5S BAG paste used in the present study is highly biocompatible, it induces hydroxyapatite formation when brought in contact with saliva. The newly formed hydroxyapatite is nearly identical chemically and structurally to that of the natural tooth. 4S5S BAG paste had been confirmed by previous studies its efficacy in enamel re-mineralization (Krishnan and Lakshmi, 2013; Milly et al., 2015; Bakhsh et al., 2017; Sfalcin et al., 2019).

Er,Cr:YSGG laser used in the present study is best absorbed by water and hydroxyl radical in the hydroxyapatite crystals with minimal thermal damage to pulp and surrounding tissues. It enhances enamel re-mineralization by its photochemical and photomechanical effects. It reduces enamel permeability and solubility as a result of melting, fusion and recrystallization of enamel crystals which seals the enamel surface (Hossain et al., 2003; Ana et al., 2006; Subramaniam et al., 2014; Chand et al., 2016). Laser parameters used in the ongoing study, were sub-ablative to avoid enamel damage based on the parameters used Molaasadollah et al., 2017 study in treatment of WSLs.

In previous studies Scanning electron microscope was used to assess re-mineralized enamel surface morphologically (Bishara and Ostoby, 2008; de Marsillac and de Sousa Vieira, 2013; Güçlü et al., 2017; Almosa et al., 2018; Perdigao, 2020). In the here in study stereomicroscope was used. The advantage of stereomicroscope over Scanning electron microscope used in previous studies, that it detects the esthetic results on outer enamel surface upon different enamel re-mineralizing treatments used. Moreover, stereomicroscope was used to detect the extent of re-mineralizing effect in terms of length and area in enamel subsurface.

In the present study, stereomicroscopic results of enamel surface and dye penetration of subsurface as shown in fig. (1) and statistical results as shown in fig. ( $2 \& 3)$ and table ( $3 \& 4)$. Although Er,Cr:YSGG laser $(0.5 \mathrm{~W}, 20 \mathrm{~Hz}, 10 \mathrm{~s})$ was effective on completely re-mineralizing and obliterating enamel surface and subsurface with complete disappearance of WSLs. When laser was used alone with the selected parameters, cracks and melting was induced on outer enamel surface rendering it with poor esthetics. Whereas, upon applying 4S5S BAG paste before laser irradiation, better esthetics was obtained with better translucent enamel surface. On the other hand, when the paste was applied after laser irradiation homogenous enamel surface was obtained but with more radio-opaque enamel surface. Moreover, using 4S5S BAG paste only partially re-mineralized enamel surface and subsurface with a little evidence of WSLs on outer enamel surface showing less M.B dye penetration in enamel subsurface.

The results of the current study were in agreement with Moslemi et al., 2009; Poosti et al., 2014 studies who reported that combining re-mineralizing topical agents with Er,Cr:YSGG or fractional $\mathrm{CO}_{2}$ laser enhanced enamel WSLs acid resistance more than either re-mineralizing topical agents treatment or laser treatment was used alone. The results of the existing study were not in agreement with Santos et al., 2014; Molaasadollah et al., 2017 and Shihabi et al., 2020, where combining laser with topical re-mineralizing agents didn't enhance enamel re-mineralization. As, the laser wave length used (Nd:YAG laser) is poorly absorbed by enamel surface and the other wavelengths parameters (Er,Cr:YSGG and Er:YAG )were not capable to achieve the desired effect.

Er, Cr:YSGG $(0.5 \mathrm{~W}, 20 \mathrm{~Hz}, 10 \mathrm{~s})$ laser results of the present study were coincided with Kaur et al., 2017, upon using different wavelength $\left(\mathrm{CO}_{2}\right.$ 
laser) which revealed a melted enamel appearance with fine cracks and fissures, but was not coincided upon using Er, Cr:YSGG with different parameters ( $0.75 \mathrm{~W}, 20 \mathrm{HZ}$ for 20 seconds) which revealed a glossy, homogenous enamel surface with well coalesced enamel rods. 4S5S BAG paste results when used alone also agreed with Kaur et al., 2017 who detected slight areas of erosions upon treating enamel surface with fluoride varnish. These Findings indicate that the use of laser in combination of re-mineralizing pastes or gels give better results than using laser alone. The better esthetic results of Er, Cr:YSGG laser alone in Kaur et al., 2017 study with a slight increased parameters than used in the present study could be related that study was carried in vivo regarding tooth vitality and the action of natural saliva in the oral cavity. Furthermore, Geraldo-Martins et al., 2013 findings could interpret the poor esthetics of using laser alone with $20 \%$ Air and $10 \%$ water in the present study. The authors advocated that the use of Er, Cr:YSGG with energy densities $0.25-0.5 \mathrm{~W}$ with no water coolant and no air flow were capable of increasing the acid resistance of human enamel. As, the presence of water during irradiation makes it difficult to obtain an enamel surface more resistant to acids.

Stereomicroscopic M.B dye penetration results of the current study were matching to Schmidlin et al., 2004; Somasundaram et al., 2013 and Güçlü et al., 2018; Fekrazad and Ebrahimpour, 2014 results, were the mean dye penetration depth was decreased upon pre-conditioning enamel surface with Er:YAG, Er,Cr:YSGG and carbon dioxide laser and topical re-mineralizing agents either alone or when combined together compared to control group. Where the lowest mean value was obtained upon combining laser with topical remineralizing agents. In contrary, Dostálová et al., 1998 and Santos et al., 2014 results were not in accordance to that of the present study, as the authors used etching parameters of laser rather than ablation or sub ablation parameters. Moreover, the wave lengths used in the previous studies were not well absorbed by enamel to attain enamel WSLs acid resistance.

The stereomicroscope M.B dye penetration of enamel subsurface results supports the stereomicroscope of enamel outer surface results. Regarding the properties of 4S5S BAG and the nature of enamel rod crystals reported by Dorozhkin et al., 2009; Bakry et al., 2014; Abbasi et al., 2015; Milly et al., 2015; Khalid et al., 2017; Afsheen et al., 2018 and Sfalcin et al., 2019. Where, the minimal dye penetration in group 4 and 2 could be related to the $4 \mathrm{~S} 5 \mathrm{~S}$ BAG paste interaction with enamel crystals growth and ionic exchange. These findings also suggests the presence of a degree of permeability to allow attraction of ions on the outer enamel surface, thus creating enamel hydroxyapatite crystals similar to that of normal enamel. Whereas absence of M.B dye penetration obtained in group 3 and 5 was when laser was used alone or before 4S5S BAG paste application due to complete obliteration of enamel subsurface as a result of enamel melting.

The EDXA results of the herein study as shown in fig. (4, 5, $6 \& 7)$ and tables (5,6,7 \& 8) acknowledged that, the highest $\mathrm{Ca}, \mathrm{Ca} / \mathrm{P}$ ratio mass $\%$ in group 4 (45S5 BAG paste treatment before) followed by group 5 (45S5 BAG paste treatment after Er,Cr:YSGG), 3 (Laser only), 2 (4S5S BAG paste only) in descending order and there were no statistical significance between group 4 and 5 . The previous results were in accord with Guimarães et al, 2011; Mohan et al., 2014; Narayana et al., 2014; Asl-Aminabadi et al., 2015; Zhang et al., 2018; Davari et al., 2019; El Mansy et al., 2019; Ghadirian et al., 2020 studies, who obtained an increased $\mathrm{Ca}, \mathrm{P}$ and $\mathrm{Ca} / \mathrm{P}$ ratio and decreased $\mathrm{C} \%$ upon combining different laser wave lengths with topical re-mineralizing agents rather than, when either laser or topical re-mineralizing agent was used alone. In contrary, These EDXA results of the current were not in agreement with Lara-Carrillo et al., 2016 and Ahrari et al., 2018 results when low level laser was used either alone or in combination topical re-mineralizing agent as the suggested wave 
length was poorly absorbed by enamel.

Regarding C \%, the ongoing study results were supported by Contreras-Bulnes et al., 2012; Zulkifli et al., 2015 and Al-Hadeethi et Al., 2016 investigations who found the highest $\mathrm{C} \%$ when laser was used alone instead of using laser in combination with other topical re-mineralizing agents. The increased $\mathrm{C} \%$ was related to crater appearance as a result of enamel ablation and its surrounding thermal damage. The prior authors suggested that the carbon atomic \% is an important factor because the increase in carbon atomic \% might indicate burning. This is due to the melting of sample surface, which is increased when energy density was increased, these findings are confirmed by stereomicroscopic enamel melting results of group 3 in the current study. However, Featherstone et al., 2001; Bachmann et al., 2004; Bağlar, 2018; Zuerlein et al., 1999 and Shihabi et al., 2020 suggested that the effectiveness of Er,Cr:YSGG laser in enamel re-mineralization is due to crystalline changes in enamel microstructure rendering it more re-mineralized and resistant to acids. The previously mentioned studies supported the decreased $\mathrm{C} \%$ upon using 4S5S BAG either before or after Er,Cr,YSGG (group 4 and 5 respectively) which revealed a decreased $\mathrm{C} \%$ and increased $\mathrm{Ca}$ and $\mathrm{P}$ and $\mathrm{Ca} / \mathrm{P}$ ratio mass $\%$.

The normal enamel $\mathrm{Ca} / \mathrm{P}$ ratio with nonsignificant increase in mass $\%$ of the ongoing study suggests that a favorable re-mineralization had occurred in all experimental groups with the best value in group 4 followed by group 5, 3 and 2 respectively. These results were supported Hossain et al., 2003; Soares et al., 2009 and Mohan et Al., 2014 studies on enamel surface, where $\mathrm{Ca} / \mathrm{P}$ ratio had increased but without statistical significant upon comparing the application of laser irradiation using different wave lengths either alone or in combination with other topical re-mineralizing agents. The normal $\mathrm{Ca} / \mathrm{P}$ ratio which ranges from 1.67 up to 2 was supported by Dorozhkin et al., 2009; Poorni et al., 2010; Klimuszko et al., 2018 and Arifa et al , 2019 studies, which was in agreement with the obtained $\mathrm{Ca} / \mathrm{P}$ ratio mass $\%$ of the current study .

The EDXA results of all groups in the present study supports the obtained stereomicroscopic results of enamel surface and subsurface structures in the current study. Where as, adding 4S5S BAG in combination with laser was more beneficial than using either laser alone or using 4S5S BAG alone, such combination increases re-mineralization effect by increasing $\mathrm{Ca}, \mathrm{P} \%$. While $\mathrm{Ca} / \mathrm{P}$ ratio\% was increased but within normal ratio indicating favourable re-mineralizing effect and the least value of $\mathrm{C} \%$ value was obtained indicating the least burning effect. The best esthetic result was obtained upon applying 4S5S BAG paste before Er,Cr,YSGG laser with more translucent enamel. Since, the degree of enamel translucency depends on enamel crystals homogenecity (Orban et Al., 1991; Berkovitz et al., 2017). The translucent appearance of enamel when the paste was applied before laser could be due to higher degree of enamel crystal lattice homgenecity obtained by 4S5S BAG paste remineralized layer, which was further enhanced by laser irradiation. Suggesting that, the enamel translucency had been preserved as a result of Bakry et al., 2014; Milly et al., 2015 and Sfalcin et al., 2019 findings who postulated that, the changes which occurred in enamel crystal lattice by the 4S5S BAG paste was nearly similar to that of normal enamel crystal lattice. While, when the enamel surface was lased first, enamel homogenecity was altered and signs of cracks and melting might had occurred in accordance to Hirota et al., 2003; Coluzzi, 2004; Zulkifli et al., 2015 ; Al-Hadeethi et Al., 2016 findings who affirmed that when Er,Cr,YSGG laser interacts with enamel surface, micro-explosions occurs within the tissue with destruction of mineral matrix which resulted in melted enamel surface with cracks, thus applying the paste after laser irradiation had markedly altered enamel crystal lattice homgenecity, rendering it radio-opaque. 


\section{CONCLUSIONS}

1. 45S5 BAG paste treatment after Er,Cr:YSGG $(\lambda=2780 \mathrm{~nm}, 0.5 \mathrm{~W}, 20 \mathrm{~Hz}, 10 \mathrm{~s})$ laser showed the radio-opaque outer enamel surface, complete absence of WSLs and completely remineralized subsurface structures. Moreover, the least amount of $\mathrm{C}$ mass $\%$ and increased $\mathrm{Ca}, \mathrm{P} \& \mathrm{Ca} / \mathrm{P}$ ratio mass $\%$.

2. 45S5 BAG paste treatment before Er,Cr:YSGG $(\lambda=2780 \mathrm{~nm}, 0.5 \mathrm{~W}, 20 \mathrm{~Hz}, 10 \mathrm{~s})$ laser showed more translucent outer enamel surface, best remineralized outer enamel surface in $\mathrm{Ca}, \mathrm{P} \&$ $\mathrm{Ca} / \mathrm{P}$ ratio mass $\%$ and less remineralized enamel subsurface structure indicated by little M.B dye penetration and a little increase in $\mathrm{C} \%$.

3. Er,Cr:YSGG $(\lambda=2780 \mathrm{~nm}, 0.5 \mathrm{~W}, 20 \mathrm{~Hz}, 10 \mathrm{~s})$ laser alone showed complete remineraliztaion of outer enamel surface and subsurface structures, but poor esthetic results by the induced cracks, enamel melting signs on outer enamel surface and increased $\mathrm{C}$ mass $\%$.

4. 45S5 BAG paste treatment alone gave poor esthetic and remineralization results, where remnants of WSLs were still present on outer enamel surface with least amount of $\mathrm{Ca}, \mathrm{P}$, $\mathrm{Ca} / \mathrm{P}$ ratio mass $\%$ and increased $\mathrm{C}$ mass $\%$. Moreover, the least amount reminrealization in enamel subsurface which was also detected by the increased amount of M.B. dye penetration in enamel subsurface.

\section{RECOMMENDATIONS:}

1. Er,Cr:YSGG $(\lambda=2780 \mathrm{~nm})$ laser is a valuable tool for re-mineralizing enamel WSLs, that the operator should be aware of the best irradiation settings for a specific clinical application.

2. Further studies are needed upon decreasing Er,Cr:YSGG $(\lambda=2780 \mathrm{~nm})$ laser parameters regarding the power, frequency and time than used in the present study to detect the best esthetic, homogenous, translucent outer enamel surface results.

\section{REFERENCES}

1. Abbasi, Z., Bahrololoom, M. E., Shariat, M. H., \& Bagheri, R. (2015). Bioactive glasses in dentistry: A review. Journal of Dental Biomaterials, 2(1), 1-9.

2. Abbassy, M. A., Bakry, A. S., Alshehri, N. I., Alghamdi, T. M., Rafiq, S. A., Aljeddawi, D. H., Nujaim, D. S., \& Hassan, A. H. (2019). 45S5 Bioglass paste is capable of protecting the enamel surrounding orthodontic brackets against erosive challenge. Journal of Orthodontic Science, 8 .

3. Afsheen, S., Tahir, M. B., Iqbal, T., Firdous, S., Rehman, J.-U., Khan, H. M. N. U. H., Abrar, M., Naeem, M., \& Rafique, M. S. (2018). Morphological, structural and hardness changes of human dental enamel irradiated with a Nd:YAG laser. Laser Physics, 28(12), 126004. https://doi. org/10.1088/1555-6611/aae054

4. Ahrari, F., Mohammadipour, H.-S., Hajimomenian, L., \& Fallah-Rastegar, A. (2018). The effect of diode laser irradiation associated with photoabsorbing agents containing remineralizing materials on microhardness, morphology and chemical structure of early enamel caries. Journal of Clinical and Experimental Dentistry, 10(10), e955.

5. Al-Hadeethi, Y., Al-Jedani, S., Razvi, M. A. N., Saeed, A., Abdel-Daiem, A. M., Ansari, M. S., ... \& Al-Mujtaba, A. (2016). Data fitting to study ablated hard dental tissues by nanosecond laser irradiation. PLoS One, 11(5), e0156093.

6. Allam, G. G., \& Aziz, A. F. A. (2018). Comparing topical fluoride application, laser irradiation and their combined effect on remineralisation of enamel. Future Dental Journal, 4(2), 318-323.

7. Almosa, N. A., Alqasir, A. M., Aldekhayyil, M. A., Aljelayel, A., \& Aldosari, M. A. (2019). Enamel demineralization around two different orthodontic bracket adhesive systems: An in vivo study. The Saudi dental journal, 31(1), 99-104.

8. Arifa, M. K., Ephraim, R., \& Rajamani, T. (2019). Recent advances in dental hard tissue remineralization: a review of literature. International Journal of Clinical Pediatric Dentistry, 12(2), 139.

9. Asl-Aminabadi, N., Najafpour, E., Samiei, M., Erfanparast, L., Anoush, S., Jamali, Z., Pournaghi-Azar, F., \& Ghertasi-Oskouei, S. (2015). Laser-Casein phosphopeptide effect on remineralization of early enamel lesions in primary teeth. Journal of Clinical and Experimental Dentistry, 7(2), e261.

10. Bakry, A S, Marghalani, H. Y., Amin, O. A., \& Tagami, J. (2014). The effect of a bioglass paste on enamel exposed to erosive challenge. Journal of Dentistry, 42(11), 1458-1463. 
11. Bakry, A S, Tamura, Y., Otsuki, M., Kasugai, S., Ohya, K., \& Tagami, J. (2011). Cytotoxicity of 45S5 bioglass paste used for dentine hypersensitivity treatment. Journal of Dentistry, 39(9), 599-603. https://doi.org/10.1016/j. jdent.2011.06.003.

12. Bakry, A S., \& Abbassy, M. A. (2018). Increasing the efficiency of CPP-ACP to remineralize enamel white spot lesions. Journal of Dentistry, 76, 52-57. https://doi. org/10.1016/j.jdent.2018.06.006.

13. Belikov, A. V., Altshuler, G. B., \& Grishin, V. V. (2008). Method and Apparatus for Tooth Rejuvenation and Hard Tissue Modification.

14. Berkovitz, B. K., Holland, G. R., \& Moxham, B. J. (2017). Oral Anatomy, Histology and Embryology E-Book. Elsevier Health Sciences.

15. Bishara, S. E., \& Ostby, A. W. (2008, September). White spot lesions: formation, prevention, and treatment. In Seminars in orthodontics (Vol. 14, No. 3, pp. 174-182). WB Saunders.

16. Borges, A. B., Caneppele, T. M. F., Masterson, D., \& Maia, L. C. (2017). Is resin infiltration an effective esthetic treatment for enamel development defects and white spot lesions? A systematic review. Journal of Dentistry, 56, 1118.

17. Bulnes Rosalia Conteras et al (2012). Structural Change on Human Dental Enamel Treated with Er:YAG, CO2 laser and Premineralizing Solution : EDS Analysis. Mexico.

18. Çiftçi, Z. Z., Hanimeli, S., Karayilmaz, H., \& Güngör, Ö. (2018). The efficacy of resin infiltrate on the treatment of white spot lesions and developmental opacities. Nigerian Journal of Clinical Practice, 21(11), 1444-1449.

19. Coluzzi, D. J. (2004). Fundamentals of dental lasers: Science and instruments. Dental Clinics of North America, 48(4), 751-70.

20. Contreras-Bulnes, R., Olea-Mejía, O. F., RodríguezVilchis, L. E., Scougall-Vilchis, R. J., \& Centeno-Pedzara, C. (2012). Structural changes on human dental enamel treated with Er: YAG, $\mathrm{CO} 2$ lasers and remineralizing solution: EDS analysis. Oral Health Care-Prosthodontics, Periodontology, Biology, Research and Systemic Conditions.

21. Davari, A., Daneshkazemi, A., \& Shafiee, F. (2019). Evaluating the Effects of Casein Phosphopeptide Amorphous Calcium Phosphate Paste and Nano-hydroxyapatite Solutions on the Re-mineralization of Synthetic Primary Caries in Enamel. Journal of Research in Medical and Dental Science, 7(2), 62-69.
22. de Marsillac, M. D. W. S., \& de Sousa Vieira, R. (2013). Assesment of artificial caries lesions through scanning electron microscopy and cross-sectional microhardness test. Indian Journal of Dental Research, 24(2), 249.

23. Dorozhkin, S. V. (2009). Calcium orthophosphates in nature, biology and medicine. Materials, 2(2), 399-498.

24. Dostálová, T., Jelínková, H., Krejsa, O., Hamal, K., í Kubelka, J., \& Procházka, S. (1998). ER: YAG LASER ETCHING OF ENAMEL. Scanning Microscopy. 12(2), 309-315.

25. Ebrahimi, M., Mehrabkhani, M., Ahrari, F., Parisay, I., \& Jahantigh, M. (2017). The effects of three re-mineralizing agents on regression of white spot lesions in children: A two-week, single-blind, randomized clinical trial. Journal of Clinical and Experimental Dentistry, 9(5), e641.

26. El Mansy, M. M., Gheith, M., El Yazeed, A. M., \& Farag, D. B. (2019). Influence of Er, Cr: YSGG (2780 nm) and Nanosecond Nd: YAG Laser (1064 nm) Irradiation on Enamel Acid Resistance: Morphological and Elemental Analysis. Open access Macedonian journal of medical sciences, 7(11), 1828.

27. Fekrazad, R., \& Ebrahimpour, L. (2014). Evaluation of acquired acid resistance of enamel surrounding orthodontic brackets irradiated by laser and fluoride application. Lasers in Medical Science, 29(6), 1793-1798.

28. Fried, D. (2005). Laser processing of dental hard tissues. Photon Processing in Microelectronics and Photonics IV, 5713, 259-269.

29. Geraldo-Martins, V. R., Lepri, C. P., \& Palma-Dibb, R. G. (2013). Influence of Er, Cr: YSGG laser irradiation on enamel caries prevention. Lasers in Medical Science, 28(1), 33-39.

30. Ghadirian, H., Geramy, A., Shallal, W., Heidari, S., Noshiri, N., \& Keshvad, M. A. (2020). The Effect of Remineralizing Agents With/Without CO2 Laser Irradiation on Structural and Mechanical Properties of Enamel and its Shear Bond Strength to Orthodontic Brackets. Journal of Lasers in Medical Sciences, 11(2), 144.

31. Gillgrass, T. J., Benington, P. C. M., Millett, D. T., Newell, J., \& Gilmour, W. H. (2001). Modified composite or conventional glass ionomer for band cementation? A comparative clinical trial. American Journal of Orthodontics and Dentofacial Orthopedics, 120(1), 49-53.

32. Giray, F. E., Durhan, M., Haznedaroglu, E., Durmus, B., Kalyoncu, I., \& Tanboga, I. (n.d.). Resin Infiltration Technique and Fluoride Varnish on White Spot Lesions in Children: Preliminary Findings of a Randomized Clinical. 6. 
33. Guclu, Z. A., Gjorgievska, E. S., \& Coleman, N. J. (2017). An in vitro comparison of the enamel remineralisation potential of bioactive glass, hydroxyapatite and CPP-ACP.

34. Guimarães, G. S., Morais, L. S. D., Elias, C. N., Pérez, C. A. D. C., \& Bolognese, A. M. (2011). Chemical and morphological analysis of the human dental enamel treated with argon laser during orthodontic bonding. Dental Press Journal of Orthodontics, 16(2), 100-107.

35. Hench, L. L. (2006). The story of Bioglass $®$. Journal of Materials Science: Materials in Medicine, 17(11), 967-978.

36. Hirota, F., \& Furumoto, K. (2003). Temperature rise caused by laser (CO2, Nd: YAG, Er: YAG) irradiation of teeth. International Congress Series, 1248, 301-304.

37. Hossain, M., Nakamura, Y., Kimura, Y., Yamada, Y., Kawanaka, T., \& Matsumoto, K. (2001). Effect of pulsed $\mathrm{Nd}$ : YAG laser irradiation on acid demineralization of enamel and dentin. Journal of Clinical Laser Medicine \& Surgery, 19(2), 105-108.

38. Kaur, T. (2017). SEM Evaluation of Enamel Surface Changes and Enamel Microhardness around Orthodontic Brackets after Application of CO2 Laser, Er,Cr:YSGG Laser and Fluoride Varnish: An In vivo Study. Journal of clinical and diagnostic research. https://doi.org/10.7860/ JCDR/2017/30292.10603

39. Kawasaki, K., Tanaka, Y., \& Takagi, O. (2000). Crystallographic analysis of demineralized human enamel treated by laser-irradiation or remineralization. Archives of Oral Biology, 45(9), 797-804.

40. Khalid, M. D., Khurshid,Z., Zafar, M. S., Farooq, I., Khan, R. S., \& Najmi, A. (2017). Bioactive Glasses and their Applications in Dentistry. Journal of The Pakistan Dental Association, 26(1), 32-38. https://doi.org/10.25301/ JPDA.261.32

41. Klimuszko E., Orywal, K., Sierpinska, T., Sidun, J., \& Golebiewska, M. (2018). Evaluation of calcium and magnesium contents in tooth enamel without any pathological changes: in vitro preliminary study. Odontology, 106(4), 369-376

42. Krishnan, V., \& Lakshmi, T. (2013). Bioglass: A novel biocompatible innovation. Journal of Advanced Pharmaceutical Technology \& Research, 4(2), 78. https://doi. org/10.4103/2231-4040.111523

43. Lara-Carrilloa, E., Doroteo-Chimalb, C., Lopez-Gonzaleza, S., Morales-Luckiec, R. A., Olea-Mejiac, O. F., Kubodera-Itoa, T., \& Medina-Solisd, C. E. (2016). Remineralization effect of low-level laser and amorphous sodium-calcium-phosphosilicate paste in teeth with fixed orthodontic appliances. Tanta Dental Journal, 13(1), 55.
44. Maung, N. L., Wohland, T., \& Hsu, C.-Y. (2007). Enamel diffusion modulated by Er: YAG laser:(Part 1)-FRAP. Journal of Dentistry, 35(10), 787-793.

45. Milly, H., Festy, F., Andiappan, M., Watson, T. F., Thompson, I., \& Banerjee, A. (2015). Surface pre-conditioning with bioactive glass air-abrasion can enhance enamel white spot lesion remineralization. Dental Materials, 31(5), 522-533.

46. Milly, H., Festy, F., Andiappan, M., Watson, T. F., Thompson, I., \& Banerjee, A. (2015. Surface pre-conditioning with bioactive glass air-abrasion can enhance enamel white spot lesion remineralization. Dental Materials, 31(5), 522-533.

47. Milly, H., Festy, F., Watson, T. F., Thompson, I., \& Banerjee, A. (2014). Enamel white spot lesions can remineralise using bio-active glass and polyacrylic acid-modified bioactive glass powders. Journal of Dentistry, 42(2), 158-166.

48. Mohan, A. G., Ebenezar, A. R., Ghani, M. F., Martina, L., Narayanan, A., \& Mony, B. (2014). Surface and mineral changes of enamel with different re-mineralizing agents in conjunction with carbon-dioxide laser. European Journal of Dentistry, 8(1), 118.

49. Mohan, A. G., Ebenezar, A. R., Ghani, M. F., Martina, L., Narayanan, A., \& Mony, B. (2014). Surface and mineral changes of enamel with different re-mineralizing agents in conjunction with carbon-dioxide laser. European Journal of Dentistry, 8(1), 118.

50. Molaasadollah, F., Asnaashari, M., Mashhadi Abbas, F., \& Jafary, M. (2017). In Vitro Comparison Of Fluoride Gel Alone and in Combination With Er,Cr:YSGG Laser on Reducing White Spot Lesions in Primary Teeth. Journal of Lasers in Medical Sciences, 8(4), 160-165. https://doi. org/10.15171/jlms.2017.29

51. Moslemi, M., Fekrazad, R., Tadayon, N., Ghorbani, M., Torabzadeh, H., \& Shadkar, M. M. (2009). Effects of ER, Cr: YSGG laser irradiation and fluoride treatment on acid resistance of the enamel. Pediatric Dentistry, 31(5), 409-413.

52. Narayana, S. S., Deepa, V. K., Ahamed, S., Sathish, E. S., Meyappan, R., \& Kumar, K. S. (2014). Remineralization efficiency of bioactive glass on artificially induced carious lesion an in-vitro study. Journal of Indian Society of Pedodontics and Preventive Dentistry, 32(1), 19.

53. Oliveira, G. M. S., Ritter, A. V., Heymann, H. O., Swift, E., Donovan, T., Brock, G., \& Wright, T. (2014). Remineralization effect of CPP-ACP and fluoride for white spot lesions in vitro. Journal of Dentistry, 42(12), 1592-1602. https://doi.org/10.1016/j.jdent.2014.09.004. 
54. Orban, Balint J., \& Bhaskar, S. N. (Eds.). (1991). Orban's oral histology and embryology (11th ed). Mosby Year Book.

55. Perdigão, J. (2020). Resin infiltration of enamel white spot lesions: An ultramorphological analysis. Journal of Esthetic and Restorative Dentistry, 32(3), 317-324.

56. Poorni, S., Kumar, R. A., Shankar, P., Indira, R., \& Ramachandran, S. (2010). Effect of $10 \%$ sodium ascorbate on the calcium: Phosphorus ratio of enamel bleached with $35 \%$ hydrogen peroxide: an in vitro quantitative energydispersive X-ray analysis. Contemporary clinical dentistry, 1(4), 223.

57. Poosti, M., Ahrari, F., Moosavi, H., \& Najjaran, H. (2014). The effect of fractional CO 2 laser irradiation on remineralization of enamel white spot lesions. Lasers in Medical Science, 29(4), 1349-1355.

58. Prasada, K. L., Penta, P. K., \& Ramya, K. M. (2018). Spectrophotometric evaluation of white spot lesion treatment using novel resin infiltration material (ICON®). Journal of Conservative Dentistry: JCD, 21(5), 531.

59. Santos Jr, D. M., Nogueira, R. D., Lepri, C. P., Gonçalves, L. S., Palma-Dibb, R. G., \& Geraldo-Martins, V. R. (2014). In vitro assessment of the acid resistance of demineralized enamel irradiated with Er, Cr: YSGG and Nd: YAG lasers. Pediatric Dentistry, 36(7), 137E-142E.

60. Schmidlin, P. R., Zehnder, M., Pasqualetti, T., Imfeld, T., \& Besek, M. J. (2004). Penetration of a bonding agent into de-and remineralized enamel in vitro. Journal of Adhesive Dentistry, 6(2).

61. Serdar-Eymirli, P., Turgut, M. D., Dolgun, A., \& Yazici, A. R. (2019a). The effect of Er, Cr: YSGG laser, fluoride, and $\mathrm{CPP}-\mathrm{ACP}$ on caries resistance of primary enamel. Lasers in Medical Science, 34(5), 881-891.

62. Sfalcin, R. A., da Silva, J. V. P., Pessoa, V. O., Santos, J., Olivan, S. R. G., Fernandes, K. P. S., Deana, A. M., Makeeva, I., Sauro, S., \& Bussadori, S. K. (2019). Remineralization of early enamel caries lesions induced by bioactive particles: an in vitro speckle analysis. Photodiagnosis and Photodynamic Therapy.

63. Shihabi, S., Abo-Arraj, E., Goodson, M., Voborna, I., \& Hamadah, O. (2020). Evaluation of the effectiveness of Er: YAG laser and calcium sodium phosphosilicate (Novamine) prophylaxis paste on remineralization of incipient enamel lesions in primary teeth: An in-vitro study. Pediatric Dental Journal.
64. Sindhu, E. (2019). Efficacy of Different Re-mineralizing Agents on Artficially Created White Spot Lesions: An In Vitro study [PhD Thesis]. Sri Ramakrishna Dental College and Hospital, Coimbatore.

65. Soares, L. E. S., do Espirito Santo, A. M., Martin, A. A., Duarte, D. A., Pacheco-Soares, C., \& Brugnera Jr, A. (2009). Dental Enamel Irradiated with Infrared Diode Laser and Photo-Absorbing Cream: Part 2-EDX Study. Photomedicine and Laser Surgery, 27(5). Sudjalim, T. R., Woods, M. G., \& Manton, D. J. (2006). Prevention of white spot lesions in orthodontic practice: A contemporary review. Australian Dental Journal, 51(4), 284-289.

66. Somasundaram, P., Vimala, N., \& Mandke, L. G. (2013). Protective potential of casein phosphopeptide amorphous calcium phosphate containing paste on enamel surfaces. Journal of conservative dentistry: JCD, 16(2), 152.

67. Sugiura, M., Kitasako, Y., Sadr, A., Shimada, Y., Sumi, Y., \& Tagami, J. (2016). White spot lesion remineralization by sugar-free chewing gum containing bio-available calcium and fluoride: A double-blind randomized controlled trial. Journal of Dentistry, 54, 86-91.

68. Taha, A. A., Fleming, P. S., Hill, R. G., \& Patel, M. P. (2018). Enamel Remineralization with Novel Bioactive Glass Air Abrasion. Journal of Dental Research, 97(13), $1438-1444$.

69. Taha, Ayam A., Patel, M. P., Hill, R. G., \& Fleming, P. S. (2017). The effect of bioactive glasses on enamel remineralization: A systematic review. Journal of Dentistry, 67, 9-17.

70. Tsai, C.-L., Lin, Y.-T., Huang, S.-T., \& Chang, H.-W. (2002). In vitro Acid Resistance of CO2and Nd-YAG Laser-Treated Human Tooth Enamel. Caries Research, 36(6), 423-429.

71. Yagci, A., Seker, E. D., Demirsoy, K. K., \& Ramoglu, S. I. (2019). Do total or partial etching procedures effect the rate of white spot lesion formation? A single-center, randomized, controlled clinical trial. The Angle Orthodontist, 89(1), 16-24. https://doi.org/10.2319/013018-84.1.

72. Zhang, J., Boyes, V., Festy, F., Lynch, R. J., Watson, T. F., $\&$ Banerjee, A. (2018). In-vitro subsurface remineralisation of artificial enamel white spot lesions pre-treated with chitosan. Dental Materials, 34(8), 1154-1167.

73. Zulkifli, N., Suhaimi, F. M., Razab, M. K. A. A., Jaafar, M. S., \& Mokhtar, N. (2015). The use of Nd: YAG laser for ablation of dental material. 